Revista Iberoamericana, Vol. LXXIV, Núm. 222, Enero-Marzo 2008, 1-

\title{
EL DESTIEMPO DE LA INVITACIÓN; \\ EN TORNO AL ÚLTIMO LIBRO DE MANUEL RAMOS OTERO ${ }^{1}$
}

\author{
POR \\ Benigno Trigo \\ Vanderbilt University
}

\begin{abstract}
de todas formas dímelo tú como los 5 lati os (sic) dímelo tú no me atormentes dímelo tú pues quiero saber qué piensas.

Ramos Otero en carta a Rosario Ferré

(21 de agosto de 1973)

dímelo / yo sé que yo te gusto / y sé que estás deseando / que yo te diga algo / dime que sí / dímelo

Johnny Rodríguez
\end{abstract}

Desde los textos clásicos de Susan Sontag sobre el cáncer, la tuberculosis, y el SIDA sabemos que nuestra sociedad moderna se defiende de la muerte poniendo en una cuarentena simbólica a ciertos sujetos considerados enfermos. La práctica se puede extender, como lo ha hecho Michel Foucault, a los comienzos de la modernidad cuando los discursos sociales de la medicina pública construyen narrativas heroicas en oposición a sujetos contaminados por lo patológico que son secuestrados en aras de la historia del progreso nacional y sus defensores. Esta forma de proteger la nación mediante la cuarentena (actual y discursiva) de sujetos sociales irredimibles, se repite, aunque modificada, en la literatura nacional y nacionalista puertorriqueña. El canon de la literatura patriarcalista puertorriqueña extiende su ojo clínico y masculino sobre un cuerpo social enfermo y femenino que aparece ya en la novela fundacional de finales de siglo diecinueve de Manuel Zeno Gandía y regresa a los textos nacionalistas de los cincuentas y sesentas de René Marqués. Pero en el caso de este cuerpo literario, no se trata de una defensa abstracta en contra de la muerte, como sugiere Sontag, sino de textos que infligen una violencia simbólicamente suicida para hacer visible los efectos de la opresión colonial ante la autoridad metropolitana.

En este ensayo intentaré mostrar que si bien Ramos Otero escribe sus primeros textos en oposición a este canon y sus figuras, no es menos cierto que también continúa el patrón

\footnotetext{
${ }^{1}$ Agradezco a Vanessa Vilches Norat y a José Quiroga por sus productivos comentarios que me dieron aliento y por las sugerencias concretas que me ayudaron a mejorar este trabajo. Rosario (Ferré) me dio generoso acceso a su epistolario privado con Manuel Ramos Otero y le estoy profundamente agradecido por ello.
} 
defensivo y violentamente melancólico de textos fundacionales y nacionalistas puertorriqueños. Siguiendo una línea de análisis psicoanalítica, hago uso de la diagnosis de un complejo de violencia defensiva que Patricia Gherovici encuentra en el sujeto puertorriqueño. Trato de mostrar que un texto como "Vida ejemplar del esclavo y del señor” (1975) es ejemplo de lo que llamo una "escritura sidosa” que pretende socavar las relaciones de poder dramatizando el placer de una violenta economía, pero que también repite las exclusiones de esa misma economía. Aprovecho conceptos trabajados por Julia Kristeva (en particular lo abyecto y el matricidio) para leer otros textos de Ramos Otero como "La casa clausurada" (1971), "La fea Otero", La novelabingo (1976), "El cuento de la mujer del mar" (1979), El libro de la muerte (1985), y "Página en blanco y staccato" (1988) como ejemplos de una forma que llamo "hospitalaria" de escribir. Esta forma de escritura es complementaria y paralela a la "sidosa”, y practica una identificación (todavía suicida) con el regreso vengativo de la madre simbólica y con su tiempo escandaloso.

Finalmente, llamo la atención sobre el cambio que representa Invitación al polvo (1991) en la escritura sidosa y hospitalaria de Ramos Otero. Cuentos como "La heredera" y "Descuento" ya detienen la repetición o el retorno obsesivo de lo abyecto y comienzan en vez lo que llamo una inversión en la escritura de Ramos Otero. Aprovechando el concepto del perdón como lo trabaja Kelly Oliver, encuentro que Ramos Otero invierte el valor anteriormente negativo y destructivo atribuido al destiempo escandaloso del cuerpo y lo vuelve una fuerza positiva, productora de un perdón necesario en estos últimos cuentos. Esta inversión alcanza su mejor expresión en el último libro de Ramos Otero donde encuentro la transformación de la invitación del cuerpo, de su ritmo y su presencia lingüística, en un modelo de escritura que trato de aprovechar como modelo de lectura en este ensayo.

\section{LA CUARENTENA}

Invitación al polvo está poblado de sujetos que se han ido, que están por irse, o amenazan con desaparecer. Son sujetos que abandonan y dejan solo al poeta y al lector. Son sujetos que ya no esperan nada y que ya no tienen tiempo. Sujetos que están presos o son víctimas de dinámicas que no sólo le quitan el tiempo, sino que también destruyen la temporalidad necesaria para el deseo y para la vida. Son sujetos pulverizados, que se hacen polvo; fantasmas ya o seres al borde de la desaparición, aparecidos o desaparecidos. Son sujetos que expresan su ansiedad ante el robo del tiempo, una ansiedad que se revela en la escritura anterior de Ramos Otero: la escritura primero alacarrera, después en staccato, y finalmente arrítmica, de sus cuentos, de su novela, de sus cartas, y también de sus poemas. “Ábreme la puerta que me voy, / que me voy, que me voy, que me voy. / Que hace cuarenta años que no soy” (56).

El último libro de poemas de Ramos Otero está lleno de sujetos deshumanizados, poblado de sujetos hechos polvo por una dinámica de opresión que opera mediante la exclusión. Los sujetos del libro son fantasmas solitarios enloquecidos por su encierro en “apartamento(s) nocturno(s) y estrecho(s)" (23), son seres vueltos “embelecos” caminantes (37), disparates que deambulan por "la tierra, la calle, la vida la que embalsama poetas" (14). Son ausencias, o sujetos que están por irse, que amenazan con irse. Son presencias 
enfermadas por la soledad y el abandono en que se quedan. Son sujetos todos enfermos por su encierro en sanatorios, en cárceles hospitalarias, en cementerios figurados y literales, seres condenados a la enfermedad de moda, a la tuberculosis, al cáncer, y al SIDA, por una profecía falsa, por una "metáfora contagiosa" (50).

Si el tuberculoso, el paciente de cáncer, y el sidoso son figuras metafóricas cuya función es proyectar la muerte a un sujeto que está fuera de nosotros, cómo sugiere Sontag, la cuarentena y su exclusión sistemática del imaginario colectivo, son las prácticas sociales de limpieza y purificación que nos ponen a salvo de su amenaza, según Ramos Otero. La cuarentena en este libro representa el tiempo imaginario oficial y regulado que desplaza la locura a "los domingos" (38). La cuarentena del marginado social es la cura segura para los que creen garantizar de esta forma su salud y normalidad. "Ser mudos es decente y libera sus conciencias” (35). Invitación al polvo coloca la cuarentena en el centro de una práctica imaginaria que contagia a ciertos sujetos: un tiempo de soledad y ayuno, un tiempo homicida de sacrificio, un tiempo que deshumaniza, un tiempo que persigue y amenaza con el final como el "enlutado inquisidor que no nos deja tranquilos" (17). Invitación al polvo se rebela en contra de este tiempo "inquisidor". El libro acusa la naturaleza soñada, imaginada del tiempo de la cuarentena, un tiempo impuesto por la autoridad de Dios y del hombre. Dios le recuerda al hombre "No te olvides del polvo... ¡Memento homo!” (34). “‘El fiel y frágil Borges’ dicen que dijo [...] que el hombre está hecho de tiempo" (69).

Los sujetos del libro, entonces, son prisioneros de este tiempo imaginario que ha reducido sus vidas a un mero anuncio de su muerte. "Hay un luto africano en el ambiente" (14). Juntos, estos sujetos componen una comunidad perseguida por el tiempo: "La persecución nos une aunque también nos señala” (17). Son una caravana que camina “con relojes de arena" (22). Son sujetos "hechos de tiempo" (40) pero temporalmente pobres: "tenemos poco tiempo y pocas cosas" (12). Son fuegos fatuos, "sin tiempo" (20), vulnerables a la "negativa del tiempo que se apega" (24), seducidos por relojes "sin hora," (12). Son sujetos que gastan "su reloj buscando gloria" (40), llorándole "al reloj la callejera condición de Lázaro” (64). Son sujetos del tiempo del paciente, sujetos que piensan "tiernamente" que el Señor también ha vivido su tiempo, "ese cansancio eterno, Señor, / que no me deja caminar [...] / esa marginación sin límite, ese asco colectivo al Kaposi Sarcoma / y a la tuberculosis, a la flaquencia de los hongos epidérmicos” (63). Son sujetos impacientes, hechos abyectos por una dinámica de exclusión que los pone en una cuarentena que reduce su tiempo al momento final.

Los sujetos pacientes de Ramos Otero se han puesto en cuarentena profilácticamente. El secuestro previene la contaminación de la historia nacional y nacionalista con su enfermedad temporal. El tiempo de la historia nacional es un tiempo lineal y cronológico, es un tiempo “monumental” (Sotomayor 2004: 291-292). Decir monumental es decir que el tiempo del discurso historiográfico es el tiempo del héroe, pero también es un tiempo sin vida, petrificado por lo lapidario, por lo objetivo, y por lo desapasionado de ese tiempo. Es un tiempo anticuario que expresa ansias “conservadoras, y no creativas” (2004: 292). Principalmente, es un tiempo "preservativo”, que encierra al antihéroe, al paciente social (marcado por estigmas como la pobreza, la homosexualidad, y la impureza racial) en un tiempo simbólico y extraño, un tiempo que lo mantiene fuera de la historia nacional, aparte 
de la nación en formación. Es un tiempo que separa del tiempo nacional al paciente para no contaminar la historia con su enfermedad. Los personajes de muchos de los cuentos de Ramos Otero se rebelan contra esta exclusión, se muestran impacientes con ella, personajes como Monserrate Álvarez, el puertorriqueño-hawaiano, encerrado en el leprocomio de Molokai por la metáfora contagiosa que es el tiempo de la cuarentena. "[E]stoy a 88 años de mi nacimiento y desde hace como cinco que los médicos me han dicho que no soy leproso, que nunca lo he sido, que lo mío es una condición del pigmento de la piel” (1988: 68). Ramos Otero interroga y desconstruye la temporalidad monumental del pensamiento nacionalista puertorriqueño mediante estos sujetos impacientes.

En Invitación al polvo, el poema que mejor ilustra el encierro, la exclusión, y la falta de tiempo del sujeto en cuarentena tal vez sea "Puerta de polvo" (56). La página del poema aparece aquí figurada como la puerta (de salida o de entrada) para un sujeto sin tiempo desde hace tiempo. "[H]ace cuarenta años que no soy” (56). Un sujeto a la intemperie o encerrado pero hecho polvo, desgarrado de sus garras minerales por el frío. La escritura del poema es la fórmula insistente de este mendigo de tiempo que pide la limosna del "ahora mismito" (56). “Ábreme la puerta que me voy, que me voy, que me voy, que me voy” (56). El ritmo irregular del poema es un golpe repetido con mayor urgencia cada vez que busca abrir la página del poema, que busca la entrada y la salida de la sangre "maliciosa", de la "tierra movediza” del recuerdo, de las "palabras busconas" (56). Su arritmia es el antídoto a los alacranes del sueño con que comienza el poema, y que amenazan con paralizar al sujeto. Las palabras en la página son como golpes que repiten los tajos dolorosos pero minúsculos del papel cuando abre la piel: la "puerta pordiosera" del sujeto abyecto del poema que "apenas ya no sangra" (56).

La mujer, el homosexual, el niño, el drogadicto, el exiliado y el negro son otros ejemplos de este sujeto impaciente con su espera del final. El polvo, el embeleco, el pájaro, el pato, el bugarrón, el hijo ilegítimo y bastardo, el escarabajo, el escorpión, el lunático, y el fantasma son sus figuras. Son todas figuras impacientes con su marginación, desprecio, desahucio, y olvido. Son figuras que piden ser convidadas al banquete social, o son figuras que no esperan más y se invitan a sí mismas, figuras "presentás”. Tal vez sea el cangrejo canceroso la figura más representativa de este sujeto. Su tiempo es como el movimiento del cangrejo, que "camina para atrás” (51). Su escritura es abiertamente confusa: "confunde las metáforas / y nunca es invitado a recitar poemas" (51). Invitación al polvo se presenta como una carta de invitación a este paciente canceroso de tiempo invertido y escritura confusa. Es un memorial, un recuerdo, de lo que se quiere olvidar, de la enfermedad que se quiere extirpar, de lo sucio, de lo abyecto, de lo negro, de lo condenado, del polvo que se quiere limpiar en rituales temporales como la Noche de San Juan que "escribe sus epitafios, poco a poco, calma a calma" (14). Es la escritura de un paciente que se niega a abrir el sobre que anuncia su muerte, y en vez abre un paréntesis que suspende el tiempo de la cuarentena. "Esta mañana llegaron los resultados / de mi muerte y todavía no abro / el sobre (el ataúd, debiera decir)” (46). Este paciente se toma libertades con el tiempo y profetiza en vez "la órbita de otra cuarentena" (64): el tiempo del escándalo. 
Ramos Otero también introduce otro sujeto e inicia otra temporalidad en Invitación al polvo. El sujeto ausente comparte el espacio de la página con un sujeto presente, con un sujeto que regresa, que vuelve, que está hecho de tiempo, que espera, que se queda solo pero invita y provoca al regreso. "Vuelvo a cantar dejando atrás la muerte / sumándome a la horrible ternura del amor / que ahora llega cuando la vida es tarde” (12). De la misma forma, el libro suspende la velocidad del juicio inquisidor, melancólico, y suicida de la escritura anterior de Ramos Otero. Invitación al polvo regresa a códigos lingüísticos abandonados y al tiempo que esos códigos representan. Tematiza, pone en evidencia, e inicia el destiempo del lenguaje poético, la clemencia y la indulgencia de un ritmo paradójico que recibe a un sujeto pulverizado y abyecto que se presupone imperdonable. Es un libro que hace visible el puente temporal entre la ausencia y la presencia, entre el que va y el que viene. "El martes que viene me voy de viaje. / No es necesario hablar de mal agüero. / Regreso al pan, al mar y al aguacero. A humedecer con polvos mi homenaje” (64). Invitación al polvo abre las puertas de un paréntesis temporal "(Tú y Yo, para nunca, entre paréntesis)" (49) que invita al sujeto enfermo a salir de una cuarentena que repite (dice en otra parte) "el triángulo color de rosa con que los homosexuales fueron marcados en los campos de concentración durante la Segunda Guerra” (1988: 108).

Invitación al polvo invita a transformar el tiempo de la cuarentena, el tiempo de lo abyecto, el tiempo que vuela, el tiempo del polvo, en el tiempo del pájaro, en el tiempo del deseo, y en el tiempo de lo propio. "Si el polvo me lo dan el polvo tomo" (34), dice el sujeto rebelde de Invitación al polvo. Como otros textos de Ramos Otero, su último poemario es una provocación irreverente, un gesto osado y atrevido de apropiación del esclavo simbólico. Pero Invitación al polvo también toma distancia de lo que llamaré la escritura sidosa de textos anteriores de Ramos Otero como, por ejemplo, "Vida ejemplar del esclavo y el señor” (publicado en la revista Zona Carga y Descarta en 1975). Estos textos contienen una estrategia defensiva, y melancólicamente suicida. Son textos que se arrogan agencia enviando un mensaje a la figura del Señor, que le devuelven a esa figura simbólica su violencia, aunque de forma invertida: "hazlo como te digo, o no lo hagas" dice la figura del esclavo (1992: 175).

Ramos Otero da testimonio del efecto destructivo y violento del discurso historiográfico, monumentalista y nacionalista en su obra. Pone de manifiesto el sacrificio que piden estos pretendidos discursos de liberación sobre cuerpos puertorriqueños tanto físicos como textuales. Ramos Otero también invierte en su escritura (y en particular en su última colección de cuentos) el efecto corrosivo que tiene ese discurso histórico sobre el cuerpo. Sotomayor llama el "cuento-cuerpo” de Ramos Otero a un testimonio, que la crítica también supone es una alternativa a la violencia de la historia monumental. ¿Pero cuán diferente realmente es esta alternativa de Ramos Otero? El "cuento-cuerpo" de Ramos Otero es un verbo alocado, una narración estructurada por el tropo de la paranomasia que hace estallar las identidades y las esencias al colocarse en el umbral de una transformación continua según Sotomayor. La escritura anterior a Invitación al polvo es una escritura sidosa en la medida que resignifica la enfermedad del SIDA, asumiéndola como modelo para una práctica contaminante de escritura que multiplica el intercambio 
de líquidos vitales: sangre, semen, y tinta (2004: 305). En este sentido, la escritura de Ramos Otero es una toma de conciencia de la mortalidad, de la condición inevitablemente degenerativa de la experiencia humana, y desde allí es una “afirmación” de la vida que nos queda, una afirmación que es también un ataque existencialista violento contra el ufanismo de las discursividades nacionalistas. Como tal, la escritura sidosa de Ramos Otero no es cualitativamente diferente a la de generaciones anteriores.

Es cierto que gracias a narradores como Ramos Otero "[h]oy contestamos de otra forma” la pregunta filosófica sobre los orígenes (la identidad y la esencia) del ser y del ser puertorriqueño (Sotomayor 1995: 210). La escritura corrosiva de Ramos Otero revela la naturaleza quimérica de todo discurso que propone un origen y que delimita una genealogía. Ramos Otero abre la posibilidad a otra forma de pensar el ser mediante su escritura sidosa. Pero también es verdad que la escritura sidosa de Ramos Otero nos deja en la misma calle sin salida de un nihilismo existencialista transgeneracional. Textos como "Vida ejemplar del esclavo y el señor" expresan formas sintomáticas de una violencia nihilistamente suicida que ya están presentes en la obra de escritores como René Marqués, principalmente en textos como "En la popa hay un cuerpo reclinado" (1959) y "Los soles truncos” (1959), pero también en su tesis sobre la docilidad del puertorriqueño.

Patricia Gherovici ha sugerido que el histrionismo de escritores como Marqués es una forma defensiva de violencia. ${ }^{2}$ La castración y el suicidio simbólico en Marqués le devuelven la violencia al Señor, sugiere Gherovici. El esclavo se pone en la posición del Soberano (y viceversa) con la intención de hacer visible tanto su violencia, como su complicidad en una economía violenta del deseo. La escritura sidosa de Ramos Otero (su obra anterior a Invitación al polvo) repite la auto-violencia melancólica de la obra de Marqués, violencia que ataca indirectamente al otro que no deja de amar. Es una forma de escritura que por un lado propone una marca distinta a la de las narraciones nacionalistas e historiográficas sobre la superficie del cuerpo simbólico del ser puertorriqueño. Pero es también una marca semejante a las etiquetas de esas narraciones por la naturaleza violentamente melancólica de su economía. Esta economía produce una auto-violencia histriónica por un lado, a la vez que oculta la violencia hecha a otro cuerpo. La escritura sidosa de Ramos Otero repite la equivalencia entre la ficción y el asesinato contenida ya en los cuentos de Marqués. Y como Marqués, la escritura sidosa de Ramos Otero también repite un matricidio simbólico que es fundacional para la literatura nacionalista puertorriqueña. $^{3}$

\footnotetext{
2 "The Puerto Rican syndrome stages a failed encounter, and could be read as a hysterical seduction of the Master, a seduction that challenges the imaginary wholeness of the Master. The return of the violence seems the only possible defense: the ataque is the way a hysteric can send back to the Master his message in an inverted form” (Gherovici 139).

${ }^{3}$ Por motivos de espacio, no me es posible desarrollar esta tesis aquí, pero mi libro Remembering Maternal Bodies, y en particular el capítulo cinco ("Memoirs for the abject; Irene Vilar's Memoria”), podría llevar al lector cierta distancia en esa dirección.
} 


\section{El HOSPITALARIO}

Desde su obra temprana, Ramos Otero ofrece una salida ambivalente a lo que llama "la encerrona" de la vida: el secuestro temporal del cual participa el canon literario nacionalista puertorriqueño. Las primeras obras de Ramos Otero dramatizan un movimiento circular entre el tiempo rápido de una escritura urbana y el tiempo detenido de una escritura canónica y familiar (Gelpí 143-144). ${ }^{4}$ El cierre del primer libro de Ramos Otero apunta a su clausura de ese tiempo familiar que lo ahoga. La forma transeúnte de su escritura es una respuesta no sólo política y social, sino también espacial a un secuestro cuya naturaleza es crucialmente temporal. Pero la escritura transeúnte de Ramos Otero no sólo deja atrás la tradición temporalmente monumentalista de la escritura en Puerto Rico. La escritura de Ramos Otero también sugiere la naturaleza materna de la resistencia a la temporalidad monumental e historicista del canon puertorriqueño. ${ }^{5}$

"La casa clausurada" representa el regreso de un tiempo reprimido. Ramos Otero subraya la naturaleza espectral de la figura materna encerrada dentro de la casa (literaria) solariega. El fantasma de la figura de la madre que persigue, obsesiona, y atormenta al narrador del cuento es el trazo mnemónico, el rastro testimonial, el recuerdo de una pérdida fundamental y radical que desestabiliza, incomoda y desplaza el centro de esa casa literaria, de la escritura paternalista puertorriqueña. La madre está ausente de ella, pero las fotos de la casa revelan su rastro. Un reloj de pared, de tiempo detenido, da testimonio de la hora exacta cuando la figura materna desapareció y la casa se clausuró. Las manecillas detenidas del reloj ya no dan la hora, pero señalan una temporalidad más verdadera. "Si entrara a la casa. ¡Qué tonto! He pensado que si entrara a la casa, buscaría el viejo reloj de pared de una de las fotos y sabría la hora exacta, sin divagar, simplemente el tiempo verdadero" (1971: 129).

El cuento deja encerrado ese tiempo devorador, y de esta forma paradójica también preserva lo que queda de él. El narrador de "La casa clausurada" deja cerrada la puerta de la casa solariega al final del cuento porque abrir la casa sería provocar la entrada a una temporalidad fulminante, sería permitir la salida a una fuerza poderosa y vengativa que regresa para hacer polvo todo lo que se le oponga, inclusive la casa misma. Pero el narrador también pospone, desplaza, la apertura de la casa para dejar intacto un "tiempo anterior a su existencia, una vida sin vida, sin velas que se prenden, un mundo sin casas clausuradas" (132). El narrador deja la casa cerrada para preservar el tiempo del mundo de la casa, por temor a perder el último rastro del fantasma materno, por miedo a que el tiempo de la casa desaparezca del todo. "El temor de que al abrir la puerta el mundo de la casa clausurada termine para siempre" (132).

La escritura temprana de Ramos Otero encuentra su origen en ese rastro doloroso que deja el cuerpo materno. La madre biográfica y la madre simbólica se confunden en los textos tempranos de Ramos Otero. "La fea Otero” se publica póstumamente en el diario

\footnotetext{
${ }^{4}$ Gelpí astutamente afirma que el cuento "La casa clausurada” representa una respuesta, reacción o reescritura del canon literario puertorriqueño, y en particular de la famosa obra de Marqués "Los soles truncos".

5 "La casa no es aquí el espacio fundado por el padre, sino el lugar asociado con la figura materna" (Gelpí 144).
} 
El Mundo como el primer capítulo de un texto inconcluso titulado Enfermedades incurables, pero debe de ser un texto antiguo ya que se menciona en una carta a Rosario Ferré fechada en $1974 .{ }^{6}$ El texto es autobiográfico y, como muchos otros ejemplos del género, se escribe sobre la piel simbólica del cuerpo biológico desaparecido de la madre biográfica, una forma de escritura que Vanessa Vilches Norat ha llamado "matergrafía” (199). Pero la escritura autobiográfica temprana de Ramos Otero no sólo tiene su origen en el vacío que deja la ausencia del cuerpo materno, no es sólo un eco que se duele por esa ausencia. Más bien, la escritura autobiográfica temprana de Ramos Otero encuentra su origen en el rastro doloroso que deja el cuerpo materno. "La fea Otero" es una escritura hospitalaria con el dolor remanente y permanente de la madre simbólica (con su ausencia, con su soledad, con su encierro), y representa una primera salida de la encerrona de la literatura paternalista puertorriqueña, de su exclusión y clausura del tiempo materno. "Escribir la historia de mi madre es volverme hospitalario con su dolor" (1990: 23).

Ramos Otero también sugiere en este texto que la escritura "hospitalaria" tiene una forma violenta, contaminada con la "enfermedad incurable" de la madre. La escritura es el "virus de la memoria que se queda dormido por tiempos y de repente contamina con su presencia los lugares privilegiados de la soledad" (23). Es una escritura modelada en el retorno repentino de una "enfermedad" que la madre borra en sus cartas nostálgicas, que esconde bajo el sueño de un hijo médico, pero que se revela en la fealdad deliberada de las fotos de su álbum de fotografías, en los cabos sueltos, y en las pausas de sus cuentos. Es una escritura formada en el reclamo y en el retorno a destiempo de una masculinidad prohibida y grabada en las fotos de la madre vestida de muñeca de porcelana a los tres años, con aire de muchacho salvaje a los siete años, y ya sin alternativas en la vida, vestida de luto por la muerte de su padre, a los dieciséis años. "Los que piensan que la vida es cronológica se equivocan" escribe Ramos Otero insistiendo en los regresos repentinos de lo materno que ha sido reprimido (21). Pero los regresos también lo devuelven a la encerrona de la que quería escapar (21).

Como "La fea Otero", La novelabingo nos regresa circularmente al encierro de la muerte. En su libro, Ramos Otero vuelve al tema de la encerrona de la vida entendida ahora como un "peregrinaje desafortunado". Vuelve al tiempo borrado de lo materno. La novela, inspirada en parte por Rayuela de Julio Cortázar, ofrece una noción del tiempo basada en el azar y una noción del lenguaje modelada en el juego de palabras. La selección azarosa de la bolita en el juego de bingo es aquí la salida figurada del tiempo de las vueltas del mundo “Mamutcandungo". La novela es un juego de palabras sostenido que lucha contra

\footnotetext{
6 “Estoy reorganizando Orgasmos prohibidos; decidí sacar La cantante de cabaret y la modelo de alta costura, Enfermedades incurables y Después de la explosión” (1974). La presencia de la figura biográfica y simbólica de la madre en los otros libros de Ramos Otero de la década del setenta me lleva a suponer que "La fea Otero", y el título mencionado en la carta, son de la misma época. Ramos Otero publica La novelabingo en 1976 y la colección de cuentos El cuento de la mujer del mar en 1979. Como digo más adelante, Ramos Otero hace referencia a un cuerpo y a un tiempo maternos en su novela, que contiene un capítulo titulado "Las patitas de Monse", tal vez en homenaje a su madre conocida como Doña Monse, “La Sultana de Manatí”. El libro de cuentos, por otro lado, no sólo reflexiona sobre una línea genealógica literaria femenina, sino que también incluye un retrato de la madre del autor en su portada.
} 
los "látidos” (sic) del violento corazón del cuerpo simbólico materno, y pretende de esta forma escapar a la "soga umbilical amarrada al Gran Círculo Madre al que tendremos que llegar en nuestro desafortunado peregrinaje". ${ }^{7}$ La tragedia de La novelabingo (y, por extensión, de la obra de Ramos Otero anterior a Invitación al polvo) es que su "remedio" nos regresa circularmente a "la soledad irredimible de la página”, como ha dicho Lilliana Ramos Collado (19). En este sentido, la "salida” de la novela no es sino el reflejo de la marca desintegradora de la escritora. La novela es el rastro abyecto de la mujer atávica, de las antepasadas, de las precursoras perdidas que Ramos Otero memorializa en sus libros. Clara Gardenia y Palmira Parés en El cuento de la mujer del mar, Penélope-Ulises en El libro de la muerte, son ejemplos de esta mujer y escritora atávica que regresa a vengar su desaparición por las dinámicas sociales que le temen al tiempo lunático de su cuerpo. El "lugar del parto" de la escritura de Ramos Otero desmistifica el tiempo linear dice Ramos Collado (30). La novelabingo, El cuento de la mujer del mar, y El libro de la muerte insisten y revelan la naturaleza repetitiva y circular de un modo escandaloso del tiempo. ${ }^{8}$

El violento regreso del destiempo materno se repite en su último libro de cuentos Página en blanco y staccato (1988). El libro describe dinámicas de opresión, catástrofes, violaciones, encierros, sacrificios, agravios remotos, que producen el tiempo de la sucesión, de la genealogía familiar, la temporalidad del progreso que lleva al futuro, que aspira a la modernidad social. Pero los agravios no se olvidan, y el libro predice su regreso, que meramente se desplaza de generación en generación, que pasa de madres a hijos que se revuelven en contra de los rituales purificadores que los produjeron: rituales científicomendelianos en el caso de Rosita Betancourt y Delta Napoleoni en "La heredera", o fanático-torquemados en el caso de Madama y Milagros Candelas en "Página en blanco y staccato”. Ángeles exterminadores como Cucumber Annie y Anita la Huerfanita pueblan este texto, "falsificándose un pasado de huérfana en busca de las calles del oro, josiándose la vida día por día con su malabarismo erótico y su mercado ambulante de pepinillos a domicilio" (104). La escritura emerge de este libro como "un verbo enloquecido, ménade de la piel” (Sotomayor 2004, 302). Pero esa bacante verbal es también una herencia materna, es una práctica violenta, intermitente, en staccato, de agujas iracundas, furiosas, vengativas, y crueles de una madre simbólica ausente (vacante) que sale de su encierro arcaico, de su roto vacío, para deshacer lo hecho, para terminar la historia, y finalmente para descontar el cuento. "Después de todo, a cada puerco le llega su sábado” (111).

\section{LA INVERSIÓN}

Pero otros cuentos de la misma colección también anticipan y contienen la clave de un ritmo y de unos latidos diferentes que Ramos Otero colocará en el centro de su último libro de poemas. "Descuento” y "Vivir del cuento” hacen referencia a la correspondencia,

\footnotetext{
${ }^{7}$ La novela no tiene números de página ni capítulos sucesivos. Por esta razón, el lector debe buscar las referencias citadas en los capítulos once ("Las patitas de Monse”) y cuarenta y cuatro ("Huácara con huácara”) respectivamente.

${ }^{8}$ Ramos Collado describe acertadamente la escritura de Ramos Otero como la "investigación de un pasado constituido por la imaginación, en ruta hacia un futuro que se sabe repetición de este pasado inventado" (18).
} 
a las cartas, como parte de una economía paradójica que impulsa o reclama la escritura. Las cartas de estos cuentos contienen o comunican un material que si no es paradójico, por lo menos es extraño en su efecto. Las cartas no sólo piden una respuesta, sino que provocan la urgencia de escribir en quien las recibe: "tenían que ser contestadas" (99). Llegan "de repente" y tienen su efecto sobre el lector "de pronto" (68). Son cartas que producen la escritura, que devuelven la humanidad, pero que también dan golpes. Son como los "mazos de cartas" de "La heredera”: "epístolas tenebrosas de una vieja amistad" (96).

Son cartas llenas de un resentimiento que se desdobla, que se repite, y que contamina a quien las recibe. Cartas que contienen el efecto paradójico de la distancia: el resentimiento de los amados ausentes. Pero que también producen el deseo de escribir y comunicar ese resentimiento (¿acaso el amor desde la distancia?): “ ¿Te acuerdas de aquello que nos escribió Monserrate Álvarez en una de sus cartas (le escribí a Magali cuando ella regresó a su apartamento [...] después de la conferencia), recuerdas el resentimiento de su frase 'el que se fue no hace falta'?” (65-66). Son cartas tenebrosas porque son doblemente negativas, porque contienen su propia negación. “'Devuélveme las cartas’. Fue como si me dijeran que no las tomara en cuenta ni que tampoco las contara” (97). Son cartas que siguen un itinerario paradójico, un desplazamiento que se niega a sí mismo, un movimiento tautológico, circular, y suicida. Son cartas que se envían con orden de regreso. Son cartas hechas de una escritura que pide ser devuelta a su lugar simbólico de origen.

Las cartas revelan la paradoja misma de la escritura que precisamente por ser sucedánea siempre está a destiempo. Las cartas son restos de lo ausente que no obstante insisten en la ficción de su presencia, restos que niegan a la vez que afirman su caducidad. Son emblemáticas de la naturaleza temporalmente paradójica no sólo de toda forma de escritura, sino del lenguaje mismo. Es por esta razón que Lacan nos recuerda en su seminario sobre "La carta robada", que las cartas son más que un medio de transporte para un mensaje. Las cartas contienen el resto extraño de lo ausente, de lo perdido, que es lo que le da sentido a la ceremonia de devolverlas "como clausura de la exhibición de los juegos de las fiestas del amor” (26). Las cartas son evidencia contundente de la naturaleza ortopédica de toda escritura y lenguaje. La carta es un pobre sustituto del origen simbólico necesariamente perdido, un facsímil, una simulación que niega una muerte que llega indefectiblemente. No obstante el efecto ofuscador del lenguaje, Lacan nos recuerda que la carta siempre llega a su destino. ${ }^{9}$

Ramos Otero es sensible al doble valor negativo de ese "resto" lacaniano representado en la escritura epistolar para invertirlo, transformándolo en su opuesto, en un exceso creativo. Ramos Otero cambia las clausuras de la carta robada de Poe y las vuelve una invitación a escribir, invitación con la que cierra sus cartas personales. “[Rosario,] tengo

\footnotetext{
${ }^{9}$ Una lectura del seminario sobre la carta robada sugeriría que la búsqueda de la carta simbólica (cifra del poder del significante y del inconsciente para Lacan) no es sino el desplazamiento de una muerte que nos capta (a pesar de, o tal vez debido a nuestros esfuerzos) en una vida que no es otra cosa que su negativo, o su forma invertida. El ministro del cuento de Poe lo dice mejor cuando explica el sentido de la figura del azar: “¿Qué eres, figura del dado que hago girar en tu encuentro (tyke) con mi fortuna? Nada, sino esa presencia de la muerte que hace de la vida humana ese emplazamiento conseguido mañana a mañana en nombre de las significaciones de las que tu signo es el cayado” (Lacan 40).
} 
que correr. Escríbeme pronto. Te quiere, Manuel” (1973). De la misma forma, y no obstante su doble negatividad (o tal vez debido a ella), los narradores de "Vivir del cuento" y "Descuento" insisten en el efecto positivo de las cartas. El narrador de "Descuento" insiste en el efecto productivo que tienen sobre él las cartas de sus amigos, de sus "testigos y primeros lectores de cuentos por correo" que reclamaban su escritura. Sobre las cartas tenebrosas de "La heredera" dice que "[n]ada puede inducir a la escritura mejor que la negación de la escritura” (97). Las cartas tienen el mismo efecto sorprendentemente positivo en los personajes de "Vivir del cuento". Monserrate Álvarez recibe una carta que llega "de repente [...] desde la colonia de Puerto Rico hasta la colonia de leprosos en Molokai" (68). La carta le devuelve "de pronto" la humanidad, y lo lleva a escribir su "cuento epistolar". Las cartas son más que el pre-texto del cuento, son también "la invitación para seguir contando” (66). Y son más que cartas de Puerto Rico, son símbolos de otro tiempo "que no fue mejor", marcas, trazos del origen perdido, imagen que corresponde a la madre ausente de Monserrate Álvarez: "Esa taza de coco es una imagen, una protección digamos, un amuleto si se quiere, es una imagen que hace que mi cabeza viaje por las noches a otro tiempo que no fue mejor pero que fue otro tiempo, tal vez porque para mí Puerto Rico y Flor María son la misma cosa” (62).

El destiempo extraño de la correspondencia en Página en blanco y staccato es el exceso rítmico que interrumpe la negatividad y la soledad del tiempo del abandono, del tiempo de la sucesión, del tiempo de la cuarentena, para seguirlo con otra temporalidad. Invitación al polvo pone en práctica este exceso temporal que llama "un cuadro invisible en el tiempo (una cuadratura de estrellas en la misma noche)", el destiempo rítmico de cartas que "llegaban y volvían a llegar" (1988: 99). Se trata del tiempo que se extiende al final de las cartas, el tiempo que corre pero desde el que se invita amorosamente al otro no sólo a escribir, sino también a escribir al sujeto. Invitación al polvo sugiere que el tiempo extraño de las cartas del origen (de la otra isla que es también la madre de Monserrate Álvarez) corresponde al ritmo de un cuerpo materno, un cuerpo simbólico que invita a escribir. "Hay (tiene que haberlo) un hoy sideral en el que pierdan / los recuerdos, en donde inventen formas nuevas de una decadencia” (1994: 71). El hoyo temporal del “Gran Círculo Madre”, la "encerrona” de la vida, se vuelve un "hoy (no en la tierra) en el que todo el que no sea / abeja no tenga que ser abejorro" en el último libro de poesía de Ramos Otero (72). El "látido" o el látigo rítmico del cuerpo materno se vuelve aquí una contracción arrítmica que provoca el agarre a la vida, un tiempo irregular que sostiene el movimiento del que se va y del que vuelve, la ida del presente y el regreso del ausente. Como el cuerpo materno, Invitación al polvo perdona al sujeto por salir, le da el impulso necesario para regresar en la escritura del poema. ${ }^{10}$ "Bañados por la nata de su tiempo /

\footnotetext{
${ }^{10}$ El efecto principal del ataque simbólico y social contra el impulso semiótico es la producción de sujetos abyectos según Kristeva; y Kelly Oliver encuentra que el efecto principal de esta producción es la naturaleza imperdonable del sujeto abyecto. Las dinámicas de opresión de la esclavitud, la colonización, y el patriarcado atacan la estructura misma de la subjetividad, según Oliver; y este ataque tiene el efecto de hacer del sujeto abyecto un ser imperdonable, un ser que no puede presumir o presuponer el perdón social. Oliver sugiere que el perdón, o más precisamente, la presuposición del perdón, es la condición necesaria para la generación del sujeto, y la presuposición del perdón es el efecto del espacio social primario. Es decir que el individuo es sujeto sólo en tanto puede
} 
tachados por la luz de su alambique / las almas lunarosas de los arrecifes / sueñan del mar de la fertilidad en el que nacen” (54).

El sujeto de Invitación al polvo asume "a plenitud su sanatorio" (38), hace del domingo su semana, se apropia del tiempo que se le ha reservado. El tiempo breve, limitado, parco, los cuarenta días, la falta de tiempo, se vuelven el destiempo de su amor, de su vida y de su escritura. El sujeto asume la ausencia del tiempo, el negativo del tiempo, como su tiempo. Hoy, el momento presente, el día, la hora, el segundo, se vuelven las coordenadas de su tiempo, revuelta íntima necesaria y suficiente para la supervivencia. “Antídotamente aprendí los ahoras" (50). El sujeto reterritorializa y se apropia del tiempo corrosivo del polvo, del tiempo prohibido de la intimidad rápida, breve, y temporera: un tiempo arcaico, el tiempo del escándalo, el tiempo de lo materno. ${ }^{11}$ Invitación al polvo opera como una cuña que vuelve a abrir una brecha temporal; y vuelve a iniciar la cesura primaria del lenguaje poético. ${ }^{12}$ Esta estrategia poética es una práctica que vuelve a encontrar, o que revela, la escansión arcaica que es el destiempo del cuerpo.

presuponer la existencia de un “espacio” social primario que perdona su trasgresión, o la revuelta íntima que es necesaria para generarse. El sujeto es y tiene sentido para sí mismo sólo mientras pueda presuponer su perdón por este espacio. El perdón, insiste Oliver, es el umbral de lo humano (180).

${ }^{11}$ En el segundo volumen de Poderes y límites del psicoanálisis (1996), Julia Kristeva sugiere que el psicoanálisis es una práctica parecida a la poesía. Según Kristeva, la poesía se aproxima a la música semiótica del cuerpo, sus cesuras son figuras para las rupturas arcaicas en el fluir de su ritmo. El psicoanálisis se aproxima a la temporalidad de esas cesuras rítmicas: a las rupturas en el fluir del tiempo que componen el ritmo del cuerpo. Según Kristeva, el psicoanálisis vuelve a encontrar el sentido de esta escansión arcaica que deja su marca escandalosa en el cuerpo. Freud llama a esta escansión arcaica un destiempo, una brecha temporal en el tiempo del sujeto que constituye el inconsciente y permanece desintegrada. "What Freud calls a (psychical and biological) death is not dead time, but has its own time. What we call a death is a scandalous temporality (Zeitlos), and since etymologically scandal is a 'detainment', we could say that it is a matter of a detained temporality, at work through consciousness and the psychical” (Kristeva, 2002: 31). Kristeva encuentra que esta escansión arcaica también constituye la cura del psicoanálisis entendida como otro proceso poético. "This scansion was no doubt indispensable in order to establish the heterogeneity of the instinctual unconscious but also a therapeutic necessity, since psychopathological symptoms and structures may appear as various inabilities to integrate the atemporal” (31). En otras palabras, la escansión arcaica del destiempo es el material temporal que constituye el inconsciente, el trabajo del análisis, y el momento de la transferencia. Según Kristeva, tanto el psicoanálisis como la poesía le deben su razón de ser y su significado (esto es, su sentido) al ritmo del cuerpo y al destiempo, la escansión arcaica, que ese ritmo expresa. Ignorar, o lo que es peor reprimir este destiempo es una operación peligrosa que borra la fuente del sentido. Las dinámicas de opresión social clausuran esta brecha necesaria, reprimen el escándalo del destiempo, y crean en su lugar sujetos temporalmente abyectos como el degenerado y el invertido sexual.

${ }^{12}$ Rubén Ríos Ávila afirma que Ramos Otero pone en práctica "una estrategia perturbadora”, “una poética de la incomodidad” en sus textos (235). En su ensayo, Ríos Ávila desarrolla las paradojas de la inestabilidad excílica, transeúnte, e indeterminada de esa escritura. Ríos Ávila afirma que Ramos Otero construye un espacio siempre incómodo en sus textos: "una casa improbable y solitaria, pero sin embargo de alguna manera segura, resguardada en la intemperie de su afuera” (234). La “seguridad” que Ríos Avila percibe oscuramente se produce a través del perdón, y es el destiempo lo que hace posible este perdón. La seguridad del perdón es precisamente lo que está de por medio en este ensayo. 
Ramos Otero revela la existencia del efecto temporalmente extraño del cuerpo en los textos que más se fortifican contra él. En este sentido, Invitación al polvo se puede interpretar como una inversión de textos defensivos que sustituyen o borran el cuerpo y su destiempo mediante una expresión poética nacionalista e identitaria. Las visiones alegóricas de A Cuba de Lola Rodríguez de Tió y Nuestra América de José Martí son ejemplos representativos de esta estrategia defensiva que Ramos Otero invierte irreverente y escandalosamente en sus poemas. Tanto A Cuba como Nuestra América son textos que producen figuras alegóricas eternas que paradójicamente borran la temporalidad inestable y precaria de la alegoría. ${ }^{13}$ Los versos nostálgicos de Rodríguez de Tió buscan producir una identidad nacional (“ide esta tierra y de la mía / hacer una patria sola!”) que encuentra su origen en la eternidad: “¡Yo cantaré en estos montes / como cantaba en mi tierra!” El texto apoteósico de Martí genera una visión de la "identidad universal del hombre”, y del origen como un padre sublime que riega su semilla por el mar y el continente, desde una eternidad que pone en evidencia las continuidades entre la colonia y la república. Ambos son textos visionarios escritos desde una temporalidad que niega el presente desolado y desquiciado del sujeto exiliado que las genera. Pero inevitablemente, ese presente incómodo deja su marca; A Cuba y Nuestra América se recuerdan por pasajes rítmicos y repetitivos que conjuran figuras descompuestas hechas de componentes desarticulados. El pájaro herido de alas desiguales, y la visión monstruosa de pecho de atleta, manos de petimetre, y frente de niño son sus disparates memorables.

Ramos Otero vuelve sobre estas figuras memorables y sobre la temporalidad incómoda que las produce. El sujeto homosexual y el petimetre que permanecen simultáneamente a la vista y escondidos por el “pájaro” de Rodríguez de Tió y la "visión” de Martí suben a la superficie en los poemas de Ramos Otero. El "pájaro" reaparece en Invitación al polvo como la figura de dos hombres que no sólo se saborean y se besan, sino que también se aman con un ritmo extraño, a destiempo, que se abrazan a lo que no perdura, a lo que ya no es, a lo que acaba. Son dos hombres que suspenden, que detienen el tiempo como el "ángel que pasa” (10), y abren con sus "alas" un tiempo nuevo. ${ }^{14}$ Por su parte, la "visión” de Martí vuelve transformada y desmitificada, como vuelve la visión de la "isla infinita" a los hombres del poema "23”. El embeleco martiano regresa aquí como flores desterradas, galeotes encerrados en una nave sin rumbo, pájaros de alas cortadas, que sabían que "lo eterno sólo dura un segundo" (33). La visión de la imperfección martiana que repetía el pretérito imperfecto del éramos termina aquí con el presente perfecto. “Éramos mucho menos de lo que ahora somos” (33). Del “éramos una visión” se pasa al "ahora somos", y del "somos" se pasa al ahora del soma, al destiempo del cuerpo, de la materia corporal de un organismo vivo que se figura como el origen de la escritura. "Con

\footnotetext{
${ }^{13}$ Para un estudio ya clásico sobre las paradojas temporales de la alegoría y sus efectos desestabilizadores en la subjetividad romántica, por favor consúltese el ensayo de Paul de Man "La retórica de la temporalidad”.

${ }^{14}$ El ángel que pasa, y que al pasar inicia el destiempo que suspende el tiempo cronológico de la cuarentena es una figura salvadora (y hermafrodita) de la obra de Ramos Otero a la que se abraza el sujeto autobiográfico de Invitación al polvo, y que aparece en su portada. Agradezco a Rosario Ferré esta observación. Para un interesante comentario sobre el efecto extraño de las fotos de los libros de Ramos Otero sobre la tradición del libro en Puerto Rico ver el libro de Gelpí (138-139).
} 
lágrimas de sangre / quise escribir la historia que ahora escribo con / sangre, con tinta sangre, del corazón” (33).

\section{LA INVITACIÓN}

Para escuchar la invitación y el reclamo del otro abyecto, el sujeto de Invitación al polvo se aproxima a la ininteligibilidad de su invitación y de su reclamo hasta identificarse con él. El sujeto se deja sentir el desasosiego de lo ininteligible en carne propia. Escuchar así es una forma del perdón. ${ }^{15}$ No sorprende entonces que el sujeto de este último libro de poemas suspenda el juicio, el tiempo cronológico del juicio final, para escuchar y contestar los reclamos de los muertos. ${ }^{16}$ "Un poema ese muerto pide ahora" (23); que acuse recibo de cartas que vienen de lejos, aceptando su invitación "a compartir los huesos del amado" (23); que reciba en su "cementerio" a poetas muertos (38); y que se identifique con los sidosos: “iQue nos llamen sidosos de una vez y todas!” (63).

Sin embargo, la escritura de este último libro no es ya una práctica sidosa. Ahora, Ramos Otero le da un "tratamiento" a la enfermedad parecido al que elaboran los artistas y escritores de la comunidad homosexual en Estados Unidos durante los años más álgidos de la crisis del SIDA. ${ }^{17}$ Darle "tratamiento" a la enfermedad es ayudar a curarla pero

\footnotetext{
${ }^{15}$ Refiriéndose al acto de escuchar en el psicoanálisis, Kristeva lo describe como una forma de perdonar: "analytical speech [...] is impossible without the forgiving and interpretation-free listening it implies on the part of the analyst, who identifies with the other's ill-being in order to make better sense of it, to the point of senselessness" (19).

${ }^{16}$ Este perdón no es el perdón de la divinidad soberana. Es un efecto, o más bien un afecto entre cuerpos, una sensación experimentada a destiempo por un sujeto que lo presupone. El perdón como lo describe Oliver en su libro Colonization of Psychic Space (2004) es una intuición que inicia y genera una temporalidad que suspende el juicio (y por lo tanto el castigo) en contra de un sujeto que afirma su rebeldía y su separación de ese espacio primario. (Quizás sea por esta razón que el sujeto emerge siempre "en proceso" como nos recuerda Kristeva.) Intuir el perdón es presumirlo, es anticiparlo, darlo por sentado. Presuponer o presumir el perdón es asumir o aceptar que éste existe y es verdadero sin tener evidencia pasada ni esperar pruebas futuras de su existencia. Por un lado, el perdón es un efecto anticipado, es anterior a su causa. Por otro, el perdón también se proyecta al pasado, es una causa que sólo se vive como un efecto. El tiempo del perdón entonces es el destiempo de la intuición, es un tiempo simultáneamente a priori y a posteriori que prescinde del futuro y del pasado a la misma vez que los genera. Oliver sugiere que el "espacio" social primario genera un tiempo paradójico que produce y presupone el perdón. "The dialectical movement between semiotic force and symbolic structure is a dialectical movement between the body and language or law that both produces and presupposes forgiveness" (188). Al vaciar a los cuerpos de sentido, al reducirlos a criptas biológicas y naturales, el "espacio" social primario se clausura. Al clausurar este "espacio", las dinámicas de opresión evacuan el destiempo del perdón que invita el sujeto a nacer.

${ }^{17}$ Quiero agradecerle a José Quiroga su comentario tras leer una versión preliminar de este ensayo, cuando me señaló la importancia de comenzar a pensar el horizonte literario de Ramos Otero desde su deuda a la comunidad de escritores que escriben en Estados Unidos en general y en Nueva York en particular durante los años ochentas y noventas. Uso el término "tratamiento" aquí según lo elabora Lisa Diedrich para referirse a una variada producción cultural que pone en escena diversas formas de "tratar" y/o representar el SIDA desde que la condición hizo su aparición en los ochentas con resultados fulminantes para ciertas comunidades marginadas en los Estados Unidos (homosexuales, haitianos, etc.).
} 
también es practicar una narrativa que le devuelva el sentido a lo aparentemente ininteligible. Escuchar de esta forma es contestar la invitación y el reclamo del otro enfermo, es una forma de escritura "cabal" que sostiene un diálogo en condiciones extremas e invita al otro abyecto a entrar en un diálogo, a contestar. Desde esta óptica, el último libro de Ramos Otero es más que otro ejemplo de los golpes fulminantes a la escritura nacionalista paternalista puertorriqueña de sus libros anteriores. El sujeto de Invitación al polvo escribe "cartas cabales" que siguen al otro con tenacidad hasta el extremo, que dan cabo, que contestan y auxilian al amado, cuando el sujeto mismo está al cabo, cuando está por morir. Para escuchar así se requiere encontrar el rastro del sentido en el desasosiego del lenguaje, se tiene que asumir el sentido en lo ininteligible. Escuchar así es también una forma de interpretación que le devuelve el sentido a lo ininteligible, el saber al cuerpo hecho polvo: "El polvo sabe que no hay anclas en la lluvia / que a nadie más le importa si ha durado / si al fin y al cabo la trampa ha terminado / para entrar a la carne sin estorbos” (21).

Escuchar y hablar, leer y escribir, invitar y contestar, son actos de interpretación que juntos logran la comunicación y el diálogo. Son actos poéticos que dependen del perdón primario del cuerpo de una madre simbólica que baña con "la nata de su tiempo" a "las almas lunarosas de los arrecifes" (54). El destiempo de las fases de ese cuerpo lunático mortifica, descompone, eclipsa y penetra pero también amamanta, seduce, ahoga, y lanza al sujeto al precipicio para que se agarre al margen de la vida (54). Los poemas de esta colección son los descendientes de esa dinastía del cuerpo simbólico materno. Mediante su destiempo, Ramos Otero escucha y responde el reclamo de los cuerpos amados desaparecidos, y le devuelve el sentido a su reclamo ininteligible. Mediante una escritura a destiempo, Ramos Otero recupera el tiempo que creía perdido. "Has descubierto el puente que da sentido al tiempo / que pensabas perdido. La prueba es el poema / que has escrito" (41).

Sus poemas son una forma de escritura que invita al polvo, que suspende el tiempo del juicio, que envía cartas cabales, y que pide una interpretación parecida: una lectura que haga de su reclamo melancólico una invitación al sentido. Desde esta perspectiva, el modelo de escritura que propone el libro es también el modelo para la lectura del poemario y para la interpretación de este ensayo. Invitación al polvo rechaza la escritura entendida como un indulto, o como la suspensión o conmutación de una pena de muerte, para invitar en vez a una reunión con el perdón del cuerpo, a una interpretación de su ritmo, de su destiempo, latente todavía en las rupturas y fragmentaciones del lenguaje poético.

Invitación al polvo, el segundo libro de poesía de Manuel Ramos Otero, se publica en 1991, un año después de su muerte. El libro extiende una invitación y hace un reclamo al lector en la forma de un latido, de un ritmo, que lo impulsa a decir quién es, que libera al lector de la vergüenza de ser un enfermo paciente atrapado en el tiempo de una cuarentena social. Invitación al polvo abre las puertas de la cárcel hospitalaria, del sanatorio y del laberinto, y le regresa su humanidad a un sujeto hecho polvo por las dinámicas de la opresión. ${ }^{18}$ En este sentido, Invitación al polvo representa un cambio

\footnotetext{
${ }^{18}$ Oliver primero hace la diagnosis de un proceso social que desconstruye al sujeto, para luego ofrecer una estrategia que vuelva a crear las condiciones necesarias para su constitución. Eventos como la
} 
esperanzador de dirección en la obra violentamente melancólica del escritor puertorriqueño y una alternativa a la literatura pugilista y suicida del nacionalismo puertorriqueño de los años cincuentas y sesentas.

\section{BiBLIOGRAFÍA}

Cortázar, Julio. Rayuela. Andrés Amoros, ed. Madrid: Cátedra, 1984.

De Man, Paul. "The Rhetoric of Temporality". Blindness and Insight: Essays in the Rhetoric of Contemporary Criticism [1971]. Wlad Godzich, intro. Minneapolis: U of Minnesota P, 1983. 187-228.

Diedrich, Lisa. Treatments. Minneapolis: U of Minnesota P, 2006.

Gelpí, Juan G. Literatura y paternalismo en Puerto Rico. Río Piedras: Editorial de la Universidad de Puerto Rico, 1993.

Gherovici, Patricia. The Puerto Rican Syndrome. Nueva York: The Other Press, 2003. Guha, Ranajit. “The Migrant’s Time”. Postcolonial Studies I/2 (1998): 155-160.

Kristeva, Julia. Powers of Horror: An Essay on Abjection [1980]. Leon S. Roudiez, trad. Nueva York: Columbia UP, 1982.

Intimate Revolt: The Powers and Limits of Psychoanalysis. Jeanine Herman, trad. Nueva York: Columbia UP, 2002.

Lacan, Jacques. Escritos [1966]. Vol. II. Tomás Segovia, trad. México, España, Argentina: Siglo XXI, 1975.

Marqués, René. Los soles truncos [1954]. San Juan: Editorial Cultural, 1983. "En la popa hay un cuerpo reclinado". Cuentos puertorriqueños de hoy [1956]. René Marqués, ed. Río Piedras: Editorial Cultural, 1981. 135-152. “El puertorriqueño dócil (literatura y realidad psicológica)”. Ensayos (1953-1971) [1960] (1972): 150-215.

Martí, José. Páginas escogidas. Max Henríquez Ureña, intro. México: Editora Nacional, 1973.

Oliver, Kelly. The Colonization of Psychic Space. Minneapolis: U of Minnesota P, 2004.

Ramos Collado, Lilliana. "Verso y prosa de Manuel Ramos Otero". Tálamos y tumbas: prosa y verso de Manuel Ramos Otero. Jalisco: Universidad de Guadalajara, 1998. 11-33.

Ramos Otero, Manuel. Concierto de metal para un recuerdo y otras orgías de soledad. San Juan: Editorial Cultural, 1971.

Carta de Manuel Ramos Otero a Rosario Ferré. Epistolario de Rosario Ferré (21 de agosto de 1973).

esclavitud, la colonización, y el patriarcado, sugiere Oliver, ponen en operación dinámicas que gradualmente abyectan, o aproximan a ciertos sujetos a la condición de objetos. En el fondo o en el centro de estas dinámicas de opresión, Oliver encuentra el ataque a un "espacio" social primario, un ataque que vacía, que priva de sentido o significado, y que finalmente clausura un impulso semiótico, inconsciente, del cuerpo: una fuerza compleja, una dinámica entre cuerpos, un evento social, que escapa la definición convencional de la palabra "espacio". Oliver elabora en este texto una lectura original de la obra de Kristeva que enfatiza tanto el efecto del impulso semiótico en el lenguaje y el sujeto como su naturaleza social. 
Carta de Manuel Ramos Otero a Rosario Ferré. Epistolario de Rosario Ferré (diciembre 1974).

La novelabingo. Nueva York: Editorial El Libro Viaje, 1976.

El cuento de la mujer del mar. Río Piedras: Ediciones Huracán, 1979.

Página en blanco y staccato [1987]. Madrid: Editorial Playor, 1988.

"La fea Otero". El Mundo. Sección "Puerto Rico Ilustrado" (28 de octubre de 1990): 21-23.

Cuentos de buena tinta. San Juan: Instituto de Cultura Puertorriqueña, 1992. Invitación al polvo [1991]. Río Piedras, Madrid: Editorial Plaza Mayor, 1994. El libro de la muerte. Tálamos y tumbas: prosa y verso de Manuel Ramos Otero [1985]. Jalisco: Universidad de Guadalajara, 1998.

Ríos Ávila, Rubén. “Dislocaciones caribeñas”. La raza cómica del sujeto en Puerto Rico. San Juan: Ediciones Callejón, 2002. 223-235.

Rodríguez de Tió, Lola. Lola Rodríguez de Tió. San Juan: Instituto de Cultura Puertorriqueña, 1960.

Sontag, Susan. Illness as Metaphor [1977]. Nueva York: Vintage, 1979. AIDS and Its Metaphors [1988]. Nueva York: Farrar, Straus and Giroux, 1989.

Sotomayor, Áurea María. "Genealogías o el suave desplazamiento de los orígenes en la narrativa de Manuel Ramos Otero”. Femina Faber: Letras, música, ley [1994]. San Juan: Ediciones Callejón, 2004. 279-306.

"La imaginería nacionalista: de la historia al relato". Hilo de Aracne; literatura puertorriqueña hoy [1991]. San Juan: Editorial de la Universidad de Puerto Rico, 1995. 179-211.

Trigo, Benigno. Remembering Maternal Bodies: Melancholy in Latina and Latin American Women's Writing. Nueva York: Palgrave Macmillan, 2006.

Vilches Norat, Vanessa. De(s)madres o el rastro materno en las escrituras del yo. Santiago: Editorial Cuarto Propio, 2003. 
